Rev. Hist., $\mathrm{N}^{\circ} 26$, vol. 2, Julio-Diciembre 2019: 33 - 51

ISSN 0717-8832

\title{
El hambre, la miseria y la Escuela: el surgimiento de las organizaciones de auxilio a la infancia escolar pobre de Concepción (1917-1929)*
}

Hunger, misery and school: the emergence of organizations helping poor school children in Concepción (1917-1929)

\section{RESUMEN:}

Laura Benedetti Reiman**

Este artículo analiza el surgimiento de las organizaciones de auxilio de la infancia escolar pobre de Concepción durante el período de la cuestión social. Para ello se contextualiza la realidad de la infancia en la ciudad, la compleja relación entre infancia popular y la escuela y finalmente las organizaciones de auxilio de la infancia pobre y escolar. Sostenemos que en el surgimiento de las organizaciones en beneficio de la infancia escolar y pobre fueron el resultado de un descubrimiento de esta, en donde convergieron diversas miradas, desde la filantrópica, el proyecto civilizador a través de la educación, elementos del pensamiento médico higienista, de la teoría de la degeneración de la raza y de las ideas eugenésicas a través de la prensa representada en "El Sur".

Palabras claves: infancia pobre-alimentación-auxilio.

\section{ABSTRACT:}

This paper analyzes the emergence of the aid to the poor childhood and the primary school enrolment in Concepción in the context of the social question. The life of childhood in the city and the difficult relationship between school enrolment and poverty are contextualized. It is argued that the emergence of the aid to the poor childhood was the result of different approaches: secular philanthropy, education through civilization, elements of hygienist medical thought, and race degeneration and eugenic ideas expressed in the newspaper "El Sur".

Key words: Poor childhood-feeding-aid

Recibido: marzo 2019

Aceptado: diciembre 2019

\footnotetext{
* Dra. en Historia, Universidad Nacional de Cuyo. Académica, Departamento de Historia, Universidad de Concepción.

** Este artículo es parte de un capítulo de la Tesis doctoral "Pobreza e historia en Chile: Representaciones, debates e interpretaciones. 1830-1930: el caso de Concepción y los centros mineros de Lota y Coronel”, Universidad Nacional de Cuyo, Mendoza, Argentina, 2019. Email: laurabenedetti@udec.cl.
} 


\section{Introducción}

El problema de la alimentación ha sido abordado de manera paulatina en la historiografía nacional ${ }^{1}$, destacándose diversas contribuciones que abordan las temáticas de nutrición, políticas de alimentación ${ }^{2}$ y su vinculación con el fortalecimiento del llamado Estado Bienestar, fuertemente influenciado por las miradas de la eugenesia ${ }^{3}$ desde los años ' 30 , pero con un importante silencio durante el período previo, siendo el hambre una categoría implícita dentro de otras problemáticas sociales abordadas, a excepción de los trabajos realizado por María Angélica Illanes ${ }^{4}$, a pesar de haber sido una variable constante en la historia nacional.

La escuela fue un elemento central dentro del discurso del progreso y civilización adoptadas por las elites latinoamericanas durante el siglo $\mathrm{XIX}^{5}$, no solo porque reproducía los conceptos de nación y patria, sino porque también "chilenizaba" ${ }^{6}$ posibilitaba la modernización del país Durante el siglo XIX a pesar de los esfuerzos del Estado por abrir escuelas, uno de los principales problemas que caracterizó al sistema de educación pública fue el escaso número de matrícula y asistencia ${ }^{8}$, además de las paupérrimas condiciones de edificios e instalaciones.

Frente a esta realidad objetiva, se alzó la problemática presencia de niños y niñas recorriendo las calles de los principales centros urbanos de la nación; la calle "era el espacio de los niños bárbaros, es decir, literalmente, de niños "extranjeros", no nombrados, no conocidos de la patria, ni de la familia, extranjeros de la sociedad y de la urbe. El reino de los niños in-digentes, es decir de los que no-son-gente" ${ }^{\prime 9}$ Fue en este objetivo, el de civilizar, que comenzó la discusión de establecer la instrucción primaria obligatoria a principios del siglo XX, en donde el Estado -de acuerdo al objetivo primerio de la ley- debía asumir la responsabilidad de la educación primaria como una realidad clave para el progreso de la nación y en el entendido

\footnotetext{
1 Yañez.2018. Gobernar es alimentar. Discursos, Legislación y políticas de Alimentación popular: Chile, 1900-1950, Santiago, América en Movimiento.

${ }^{2}$ Deichler, Claudia.2016. Historia de la alimentación popular. Dos décadas de lucha médica contra la desnutrición en el Chile urbano, 1930-1950. Santiago, Ministerio de Salud.

3 Sánchez, Marcelo.2016. Chile y Argentina en el escenario eugénico de la primera mitad del siglo XX. Tesis para optar al grado de Doctor en Estudios Latinoamericanos, Santiago, Facultad de Filosofía y Humanidades.

4 Illanes, María Angélica. 1991. Ausente señorita. El niño-chileno, la escuela -para pobres y el auxilio. Chile 18901990, Santiago, Junta Nacional de Auxilio Escolar y Becas (JUNAEB)

${ }^{5}$ Burns, Bradford.2015. La pobreza del progreso: América Latina en el siglo XIX, Siglo XXI editores.

${ }^{6}$ Pinto, Jorge. 2003. La formación del Estado y la nación y el pueblo mapuche. De la inclusión a la exclusión, Santiago, 2 a edición, Dirección de Bibliotecas, Archivos y Museos.

${ }^{7}$ Rojas, Jorge. 2016. Historia de la Infancia en el Chile Republicano, Santiago, JUNJI, pág. 162.

${ }^{8}$ Egaña, Loreto. La educación primaria y popular en Chile. Una práctica de política estatal, Santiago, Dirección de Bibliotecas, Archivos y Museos.

${ }^{9}$ Illanes, María Angélica. Ausente señorita..., p.2.
} 
que la apertura de escuelas, contribuiría de manera efectiva al cierre de cárceles ${ }^{10}$, considerando la mirada sobre la criminalidad, las condiciones de vida y el analfabetismo que alarmaba a los intelectuales chilenos; en un contexto de crisis social estructural.

Durante la segunda mitad del siglo XIX, se desarrolló en Chile la cuestión social ${ }^{11}$, entendiéndose este concepto como una forma de pobreza propia del capitalismo, manifestándose a través de la vida del conventillo -identificado como el núcleo de los problemas sociales e higiénicos-, la proliferación de enfermedades, el aumento de la mendicidad y altos índices de mortalidad, especialmente infanti ${ }^{12}$. Un punto central dentro de la cuestión social fue el paso de problemáticas que se desarrollaban en ámbito privado al espacio público ${ }^{13}$, situación que hizo posible el descubrimiento de cómo vivían y morían los integrantes de los sectores populares urbanos, posibilitando con ello el descubrimiento de la infancia popular. "El cuerpo del niño pobre será la categoría donde se buscará regenerar a toda la sociedad. La célula que, al ser salvada del a muerte, armonizaría el orden cultural y material de la civilización y salvaría lo establecido"14

Una parte fundamental de la aproximación desde la ciencia a las formas de vida de la infancia pobre , y de los sectores populares en general así como también de las altas tasas de mortalidad infantil, lo constituyó la medicina a través del discurso médico higienista ${ }^{15}$, que se plasmó de manera explícita en las diversas medidas higiénicas establecidas por los municipios durante la segunda mitad del siglo XIX: inspecciones domiciliarias, desinfecciones, inoculaciones y la ley de habitaciones obreras en 1906, acciones que tienen directa relación con los elementos constitutivos de este paradigma científico: 1) la salud de las personas depende de la calidad del ambiente en la que se desarrolle, ( existiendo ambientes sanos y malsanos), 2) la adhesión a la teoría miasmática, 3) toda propagación de enfermedad es algo evitable ,4) el Estado debe velar por la salubridad pública ${ }^{16}$. De esta manera, el higienismo constituyó un elemento base dentro de las acciones iniciales en la configuración de la biopolítica desarrollada por el Estado durante el siglo XX, en un contexto donde el conventillo y sus habitantes, especialmente los niños y las

\footnotetext{
${ }^{10}$ Salas, Darío. 1912. El problema nacional: bases para la reconstrucción de nuestro sistema escolar primario.

11 Benedetti R. 2011. La cuestión social en Concepción y en los centros mineros de Coronel y Lota 1885-1910, Concepción, Al aire libro; Grez T.1992. La cuestión social en Chile ideas y discursos precursores (1804-1902), Dirección de Archivos, Bibliotecas y Museos.

12 Rojas M. 2016. Historia de la Infancia en el Chile Republicano. Santiago, ediciones Junji, tomo I y II.

${ }^{13}$ Garcés D.2003. Crisis social y motines populares en el 1900, Santiago, LOM.

14 Illanes O.2006 Cuerpo y sangre de la política. La construcción histórica de las Visitadoras Sociales (1887-1940), Santiago, LOM, p.120

${ }^{15}$ Folchi D.2007. “La higiene, la salubridad pública y el problema de la vivienda popular en Santiago de Chile, 18431925 " en Perfiles habitacionales y condiciones ambientales. Historia urbana de Latinoamérica, siglos XVII-XX, Puebla, Benemérita Universidad de Puebla, pp.361-388.

${ }^{16}$ Ibíd., p. 364 y 365.
} 
mujeres en su rol de madres, comenzaron a ser objeto de discusión, preocupación y auxilio en las temáticas de alimentación e higiene a través de la organización de instituciones como la Sociedad Protectora de la Infancia ${ }^{17}$, Asilo de la Infancia, Gotas de leche y el Patronato Nacional de la Infancia ${ }^{18}$, donde convergieron las mujeres de la élite ${ }^{19}$ y el mundo médico, en un contexto de crisis, la cuestión social, en donde el tema del hambre también fue una problemática que buscó ser subsanada.

Al higienismo, como paradigma científico, se sumaron elementos de la teoría de la degeneración, difundida a través de la Revista Médica, que postulaba una relación directa con el alcoholismo como agente blastofórico ${ }^{20}$, causante de estigmas generacionales como " [...] niños flacos, enfermizos, debilitados en extremo", además del raquitismo, entre los sectores populares; esta mirada científica cobra especial importancia con la percepción de la nación chilena en el cambio de siglo; el cuerpo de la nación -el pueblo- está enfermo, dando signos evidentes de la decadencia de la raza, como consecuencia del desarrollo de las llamadas enfermedades de trascendencia social: alcoholismo, tuberculosis y sífilis ${ }^{21}$. La teoría de la degeneración del siglo XIX, fue el punto de conexión con los postulados eugenésicos ${ }^{22}$ que se divulgaron y trataron en el IV Congreso científico chileno: la alimentación infantil, la higiene escolar y la atención de enfermos mentales; particularmente destacamos la idea mejoría que propone la eugenesia frente a la decadencia de la raza, cuyos postulados se difundieron desde principios del siglo, para consolidarse e institucionalizarse entre 1917 y 1932 y ser un pilar fundamental en la formación de médicos en el país.

Desde los sectores liberales-radicales y desde el mundo médico se estableció la necesidad de entregar el auxilio para incorporar a la infancia popular a la escuela; este debía materializarse a partir de la entrega de alimentación y el apoyo en vestuario como elementos indispensables para evitar la deserción escolar. Estas propuestas fueron el resultado de una mirada que sostenía la importancia de la educación para dejar de ser pobre, por ello era fundamental considerar que las precarias condiciones fisiológicas de los estudiantes podrían revertirse a partir de las ollas infantiles y cantinas escolares.

\footnotetext{
17 Ibarra R. 2006. Sociedad Protectora de la infancia de Concepción: la figura de Leonor Mascayano Polanco, Concepción, Universidad de Concepción, Centro de investigación histórico en estudios regionales.

18 Illanes, María Angélica.El cuerpo y la sangre en la política.

${ }^{19}$ Salazar.2002. Historia Contemporánea de Chile IV. Hombría y feminidad, Santiago, LOM. Vicuña. 2001. La belle epoque chilena: alta sociedad y mujeres de elite en el cambio de siglo, Santiago, Sudamericana.

${ }^{20}$ Sánchez D. 2016. Chile y Argentina en el escenario eugénico de la primera mitad del siglo XX, Universidad de Chile, Tesis para optar al grado de Doctor en estudios latinoamercanos, p.21.

${ }^{21}$ Chávez, Pablo." Ilegitimidad, alcoholismo y tuberculosis: explicaciones médicas de la mortalidad infantil. Santiago de Chile (1870-1912)" Nuevo Mundo Mundos Nuevos [En línea], consultado el 11 diciembre 2019.

${ }^{22}$ Sánchez D. 2016. Obra citada p.57.
} 
Se hace necesario entonces, conocer qué instituciones auxiliaron a la infancia escolar pobre en un espacio regional, además identificar las ideas que explican su funcionamiento y prácticas. Para ello la revisión de la prensa penquista, a través del diario "El Sur" es fundamental, posibilitando no solo identificar las organizaciones, sino que además los objetivos, actividades y opiniones del cuerpo médico penquista sobre resultados específicos de la entrega de alimentación y vestuario en la población escolar que fueron publicadas en la prensa, considerando en el análisis el contexto nacional de cuestionamiento social, la crisis económica y los problemas denunciados y abordados en el "El Sur" desde la última década del siglo XIX.

\section{La infancia en Concepción: Entre el auxilio y la criminalización}

La infancia popular en Concepción irrumpió en la discusión pública a través de la prensa y de fuentes como la Junta de Beneficencia a partir de diversos fenómenos que se han abordado desde la historia tales como el abandono de infantes ${ }^{23}$, el ingreso a instituciones como la casa de huérfanos, la circulación entre nodrizas ${ }^{24}$, mendicidad, la criminalidad y el desarrollo de oficios que les exponían a los peligros de la calle, la vida mísera del conventillo y la muerte ${ }^{25}$.

La existencia de la infancia popular, como un elemento componente de los sectores populares, estuvo marcado por la precariedad y un aprendizaje temprano de sobrevivencia, la muerte constituía una amenaza permanente a consecuencia de las epidemias, la condición de miseria, la falta de cuidados maternos o ilegitimidad de su nacimiento como lo sostenía la élite

"El oficial de la tercera circunscripción del Rejistro civil informa que el año pasado inscribió 6.717 nacimientos de los cuales 3.861 eran ilejitimos. El mismo funcionario ve en esto la causa principal de la aterradora mortalidad de la infancia. Para el año pasado se inscribieron 2.177 defunciones de niños menores de 7 años sobre un total de 4.676 fallecimientos" 26 .

“...una nación que no aumente su población en proporción de sus habitantes es considerada por los estadistas como una situación poco favorable.

En el cuidado de la madre está la clave de la eliminación de la mortalidad infantil...hai que tomar en cuenta que si todas las madres cumpliesen con fidelidad sus deberes de tales, la humanidad tendría asegurado su porvenir..."27.

\footnotetext{
${ }^{23}$ Fernández, Pamela .2012. “¿Madres desnaturalizadas o socialización de la violencia? Abandono, maltrato e infanticidio en Concepción. 1840-1870", en Revista de Historia Udec №18 (enero-junio), Concepción, pp.105-137.

${ }^{24}$ Biblioteca Central Luis David Cruz Ocampo, Universidad de Concepción Actas de la Junta de Beneficencia de Concepción, 1880-1939.

${ }^{25}$ El Sur desde 1886 comenzó a publicar el listado de fallecidos diarios y las respectivas causas de muerte, además de las Ilamadas estadísticas vitales.

${ }^{26}$ Biblioteca Nacional (BN), El Sur, Concepción, 9 de mayo, 1915.

${ }^{27}$ BN, El Sur, Concepción, 16 de mayo, 1915.
} 
Frente a esta situación, diversas instituciones asumieron la responsabilidad de atender las necesidades de la infancia pobre: la Sociedad Protectora de la Infancia a través de su casa hogar, la Gota de leche Juana Ross de Edwards que no solo se preocupaba de la salud y alimentación de los niños sino que también de las madres, promoviendo la regularización de las relaciones de hecho como obligación para acceder a la atención médica y social, el Asilo de la Infancia, la Casa de Huérfanos y el Hospital de Niños, las que en su conjunto atendieron las necesidades de los más desposeídos.

Sobre la infancia popular se cernían los prejuicios morales sobre su origen, la ilegitimidad ${ }^{28}$, pero también la mirada que se tiene sobre las madres: la falta de conocimiento producto de su barbarie constituía una causa de la alta mortalidad infantil, además el ambiente insano del conventillo que no había sido erradicado ni mejorado a pesar de las medidas higiénicas aplicadas. En este tipo de vivienda la población quedaba condenada a la decadencia general.

" el desconocimiento del pueblo de la forma de la que se debe vivir. En el tugurio sucio y en el inmundo conventillo tienen su foco todas las enfermedades y su mejor desarrollo todas las epidemias, en esas habitaciones en que viven las familias en la mayor miseria y la más horrible promiscuidad, se agota el vigor de nuestra raza, se provoca la degeneración física y moral de los individuos ${ }^{29 \prime \prime}$.

Esta degeneración se hizo evidente en las inspecciones médicas que facultativos de la ciudad realizaron de manera voluntaria a los establecimientos educacionales públicos, ya que en Concepción no existía la figura del servicio médico escolar o visitación médica financiada por el Estado:

"[...] $]$ se han dedicado a practicar visitas a las escuelas a fin de prestar su ayuda profesional a aquellos niños de escasos recursos y que necesitan su atención. Uno de ellos, el oculista Sr. Daniel Palma, además de los médicos Samuel Valdivia, René Ríos y Enrique Pacheco [...]han quedado tristemente impresionados del estado de salud en que se encontraban los niños. Gran número [...] se halla atacado de enfermedades que su permanencia puede ser peligrosa para sus compañeros. Otros están afectados por afecciones que, si no son oportunamente tratadas, pueden ser de consecuencias fatales" ${ }^{30}$.

"La defectuosa organización de la familia en las clases populares se refleja manifiestamente en la población que concurre a las escuelas, [...], muchos niños enfermos, no eran pocos los tuberculosos"31

\footnotetext{
${ }^{28}$ Rojas M. 2016. Historia de la infancia en el Chile Republicano, Santiago, ediciones JUNJI, tomo II.

${ }^{29}$ BN, El Sur, Concepción, 16 de febrero, 1917.

${ }^{30}$ BN, El Sur, Concepción, 2 de febrero, 1917.

${ }^{31}$ BN, El Sur, Concepcion, 3 de julio, 1918.
} 
La presencia de niños enfermos en las escuelas fue una constante en la vida escolar ya que tres años antes de la visitación médica, una directora solicitaba la desinfección del establecimiento educacional a fin de evitar los efectos de enfermedades infectocontagiosas, "[...] no es raro ver alumnos que asisten a las escuelas con ostensibles signos externos de padecer enfermedades contajiosas" 32 .

Dichas enfermedades tenían directa relación con las condiciones de vida en el conventillo siguiendo los elementos del higienismo, la alimentación y los estigmas heredados de sus padres que identificaba la teoría de la degeneración, todo ello en un contexto donde se explicita que se hace necesario la defensa de la raza ${ }^{33}$ que se encontraba en decadencia, encontrándose las ideas de la eugenesia:

"Los niños que asisten a las escuelas apenas tienen, en muchos casos, una alimentación que merezca el nombre de tal; van a sus clases en condiciones de debilidad que no les permiten estudiar y se desarrollan en un ambiente de miseria, presas del hambre, para llegar a ser más tarde hombres raquíticos y víctimas de un sin número de enfermedades" ${ }^{34}$.

Si la mirada sobre la infancia escolar pobre era preocupante y negativa, más nefastos fueron los discursos que se construyeron en torno a aquellos infantes que no se encontraban insertos en el sistema escolar, sino que hicieron de la calle su espacio cotidiano de sobrevivencia y sociabilidad en una sociedad que estaba experimentando una severa crisis económica debido a los problemas derivados de la Primera Guerra Mundial ${ }^{35}$ y la crisis de la industria salitrera, lo cual se tradujo en el alza de los productos de primera necesidad, en un aumento de desempleados y en la agudización de la mendicidad infantil ${ }^{36}$, complementada con el desarrollo de oficios vinculados a la calle: lustrabotas y vendedores de diarios. Los niños en la calle estaban expuestos a las influencias nefastas de la delincuencia y corrupción moral. Para estos la única posibilidad de regeneración moral y de control sería la escuela, obligando la incorporación a esta a través de la persecución policial:

"Hemos dado cuenta de que el primer Alcalde ha conseguido de la intendencia que un oficial de la policía y tres agentes recorran las calles de la población citando a los padres de los niños vagos que no estén matriculados en ninguna escuela $[\ldots]^{37}$.

\footnotetext{
32 BN, El Sur, Concepción, 18 de noviembre, 1915.

${ }^{33}$ BN, El Sur, Concepción, 17 de marzo, 1917

${ }^{34}$ BN, El Sur, Concepción, 27 de mayo, 1917

${ }^{35}$ BN, El Sur, Concepción, 25 de octubre, 1916.

${ }^{36}$ BN, El Sur, Concepción, 15 de junio, 1915. El Sur, 23 de julio, 1915.El Sur, 24 de octubre, 1916.

${ }^{37}$ BN, El Sur, Concepción, 4 de septiembre, 1915.
} 
"El citado oficial, dando cumplimiento a su cometido [ la disminución de niños vagos por las calles], ha recogido desde el 30 de agosto último hasta la fecha, 381 niños comprendiendo edades de 5 a 18 años, [...] De estos 292 son analfabetos [... $]^{38}$.

La prensa celebró las gestiones desarrollada por el oficial Bastías- a quien se le encomendó la tarea de erradicar la vagancia infantil e incorporar a los niños al sistema escolar-, no solo publicando la cantidad de niños aprehendidos por vagancia, sino que además destacando un aumento significativo en la matrícula escolar; en el caso de los lustrabotas y vendedores de periódicos, también se estableció un mecanismo para promover la matrícula y asistencia a la escuela.

A pesar del aumento de la matrícula como una realidad general, no es posible afirmar la permanencia de los inscritos en los distintos establecimientos de la zona, situación que no fue mencionada en el periódico. Antes bien, se continúan realizando llamados frente al aumento de niños vagos, la importancia de la educación y la pobreza de la infancia en general.

\section{La Escuela, el hambre y la miseria de los estudiantes: el surgimiento de las organizaciones de auxilio para los escolares pobres de Concepción}

La primera década del nuevo siglo abrió la discusión pública, poniendo nuevamente en el centro al niño pobre, pero esta vez no solo desde su condición de precariedad física o de salud, sino desde su incorporación a la vida escolar, elemento clave dentro del proceso de civilización y progreso del Estado nacional, “[...] se trabó la contienda entre la calle y la escuela: un capítulo decisivo entre civilización y barbarie en el suelo americano y chileno" 39

Fue en este contexto, donde un conjunto de hombres y mujeres provenientes del mundo político (Malaquías Concha, Luis Emilio Recabarren, Darío Salas y Pedro Bannen) y médico (Eloísa Díaz), iniciaron una verdadera cruzada en pro de la infancia pobre y en edad escolar a través de dos ideas centrales: fortalecer el rol del Estado en materia de instrucción primaria y la entrega del auxilio material para asegurar la asistencia y mantención de los niños indigentes en el sistema escolar, frente a una sociedad portadora de una "miopía social", que redujo la cuestión social a una cuestión obrera, no observando la problemática en sus múltiples variables; el desafío era la creación de un sistema sólido que asegurara, a través de la obligatoriedad, la asistencia del niño pobre a la escuela, una "escuela para todos", recibiendo el socorro estatal de alimentación -dada la incompatibilidad entre hambre y aprendizaje-tal como fue planteado

\footnotetext{
${ }^{38}$ BN, El Sur, Concepción, 6 de septiembre, 1915

39 Illanes O. Ausente señorita. El niño-chileno, la escuela- para pobres y el auxilio. Chile 1890-1990, Santiago, Junta Nacional de Auxilio Escolar y Becas (JUNAEB), 1991, p.21
} 
por la Asociación de Educación Nacional a instancias de la médico Eloísa Díaz, responsable de la salud de los alumnos en las escuelas primarias de la capital.

Como fue la constante en la historia nacional durante el período estudiado, antes que el Estado asumiera la obligación del auxilio para los escolares pobres, fueron los privados quienes movidos por sentimientos filantrópicos o científicos quienes organizaron sociedades de ollas infantiles (1908), como una respuesta a la necesidad de alimentación- que era en definitiva un mecanismo clave en la asistencia del niño pobre a la escuela- propuesto e implementado por la Dra. Eloísa Díaz con su proyecto de cantinas escolares,

“Eloísa tomó finalmente la decisión. Un día guardó en el armario el maletín con fuelle, echó a la cartera el delantal casero y la cacerola grande y la cuchara de palo. Se dirigió a la calle Dolores e instaló sus nuevos instrumentos en la escuela № 97 de niños. Sus 'sentimientos caritativos' y su compromiso profesional la habían inducido a ensayar por su cuenta el régimen de la cantina escolar. Al poco tiempo se notó en el populoso barrio y pobre de Dolores cómo mejoraba la asistencia a la escuela. Con un costo de diez centavos por ración, Eloísa y sus ayudantes repartían por término medio 600 raciones mensuales" ${ }^{40}$.

El proyecto de Ley de instrucción primaria obligatoria y auxilio escolar, fue discutido entre 1909 y 1920, hasta su aprobación definitiva con una serie de modificaciones profundas. El problema de la infancia pobre en las escuelas fue apropiado por las sociedades, ya no solo era la élite la llamada a dar respuesta, sino que esta fue dada por los habitantes de los barrios donde se emplazaron los proyectos privados de auxilio a la infancia.

Mientras se discutía la ley, en Concepción llamaba la atención el deplorable estado en que asistían los estudiantes a las distintas escuelas, condición que era transversal a la infancia pobre: suciedad frente a la ausencia de hábitos privados de higiene, descalzos, harapientos y con signos evidentes de enfermedades como la tuberculosis y portadores de las llamadas epidemias escolares como la sarna y pediculosis ${ }^{41}$. No solo la presentación personal de los educandos llamaba la atención, mayor preocupación tomó el hecho de los problemas de salud derivados de una alimentación deficiente.

El problema de la instrucción del niño pobre era una realidad nacional; vista la asistencia escolar como un mecanismo efectivo en la lucha por el combate a la vagancia infantil- como fue implementada en el caso de la ciudad de Concepción-, revistó la problemática del auxilio, sobre todo la necesidad de alimentación y de asistencia médica.

“Ninguna obra puede ser tan simpática como la de proporcionar a los niños desvalidos que asisten a las escuelas una alimentación que complete la escasísima que reciben en sus

\footnotetext{
40 Ibíd., p.78.

${ }^{41}$ BN, El Sur, Concepción, 27 de mayo, 1917.
} 
hogares, porque de ellos dependen en gran parte y el porvenir de la raza y porque viene a llenar una de las necesidades más sentidas en nuestro país. Los niños que asisten a las escuelas apénas tienen, en muchos casos una alimentación que merezca el nombre de tal $[\ldots]^{\prime \prime 2}$.

Mientras la experiencia de las cantinas escolares y las ollas infantiles eran conocidas desde la primera década del siglo XX, estas no lograron desarrollarse en la ciudad de Concepción, no por falta de interés en la ciudad, sino porque como hemos revisado, otras fueron las acciones emprendidas para el auxilio de la infancia: “En Concepción es tiempo más que sobrado de que se instituya una cantina escolar, en una escuela de hombres y otra de niñas por ejemplo, se pueden escoger a los más necesitados, [...] El hambre y la miseria no son menos terribles en nuestra ciudad $[\ldots]^{\prime \prime 4}$

En Concepción existió, desde finales del siglo XIX y durante las primeras dos décadas del siglo XX, la Sociedad de Estudiantes pobres, asociación que costeaba los estudios a alumnos destacados en establecimientos de Concepción y Santiago. No centró su accionar en la infancia popular escolar, sino que estaba destinada a la educación secundaria, normalista y universitaria.

Sobre el auxilio a los niños pobres que asistían a las escuelas públicas, encontramos una única actividad, el desarrollo de una kermese ${ }^{44}$-a petición del Intendente- con el objetivo de reunir de dinero para la adquisición de ropa y calzado, desde la óptica de la filantropía: “[...] para los niños pobres de las escuelas públicas"; pero este evento constituyó un hecho aislado y no sostenido a través del tiempo.

\section{El Pan Escolar}

En octubre de 1917 la prensa informó sobre la existencia de El Pan Escolar, sociedad fundada con los objetivos de proporcionar el auxilio que el Estado negaba a la infancia pobre: alimentación y vestuario ${ }^{45}$; organizada como sociedad el 1일 de junio, inició sus acciones -como centro de operaciones- en la escuela № 39 de mujeres, con la repartición de desayunos a noventa y cinco alumnos, no solo del mismo establecimiento, sino que también de la escuela № 1 de hombres; gracias a "[...] la ayuda de los vecinos de buena voluntad fue posible ampliar el número de raciones entregadas a ciento diez niños y luego ciento cincuenta y seis, con alumnos provenientes de las escuelas [...] № 24 , № 14 , № 39 у № $1^{\prime \prime 4}$.

\footnotetext{
42 Ibíd.

43 Ibíd.

${ }^{44}$ BN, El Sur, Concepción, 30 de diciembre, 1916.

${ }^{45}$ BN, El Sur, Concepción, 3 de abril, 1919.

${ }^{46}$ BN, El Sur, Concepción, 15 de octubre, 1917.
} 
Considerando las condiciones de vida de la infancia pobre, hambre y miseria, El Pan Escolar abrió un nuevo centro de operaciones en el sector de Plaza Cruz, que atendió a los niños provenientes de los populosos -y pobres- sectores de la Pampa y Ultra Carrera, barrios caracterizados por las pendencias y las míseras condiciones materiales de sus viviendas; especificándose el número de atendidos por escuela: " 25 niños de la escuela № 11 de hombres, 25 niñas de la escuela № 13 de mujeres, 30 de la escuela № 15 de mujeres y 30 [niñas] de la № 10 de mujeres" ${ }^{\prime \prime 7}$.

A la apertura de los dos centros ya señalados, durante el año 1917, se sumaron otros dos, establecidos estratégicamente en otros puntos de la ciudad: uno en el barrio Chillancito, un sector muy apartado de la ciudad, "[...] ese barrio es habitado por niños mui indigentes [...]" ${ }^{48}$, y otro centro en la Avenida Collado, espacio suburbano, que recibió "[...] a quiénes vienen de los campos vecinos después de hacer un largo recorrido y en muchas ocasiones, sin haber tomado desayuno alguno" 49 .

A fin de dotar de vestuario a los estudiantes, El Pan Escolar contó con una sección de costura, encargada de la confección del vestuario y ropa interior, sección que fue complementada con la donación de calzado y vestuario ${ }^{50}$.

Cuadro №1: Centro de distribución de alimentos de El Pan Escolar en abril de 1919.

\begin{tabular}{|c|c|c|c|}
\hline Centros & Dirección & $\begin{array}{l}\text { Alumnos } \\
\text { inscritos }\end{array}$ & $\begin{array}{l}\text { Escuelas a las } \\
\text { que asisten }\end{array}$ \\
\hline $\begin{array}{l}\text { Escuela Superior de Mujeres } \\
\qquad \text { №3 }\end{array}$ & Las Heras 735 & 80 & №3, 23 y 40 \\
\hline Escuela Superior №5 & San Martín 228 & 125 & №5,8,21 y 22 \\
\hline Escuela Elemental №16 & Lincoyán 1147 & 100 & №11, 13, 15 у 16. \\
\hline Escuela Superior №39 & $\begin{array}{c}\text { Janequeo } \\
\text { Esquina Freire }\end{array}$ & 225 & $\begin{array}{c}\text { №12, } 24,17,29 y \\
39\end{array}$ \\
\hline Chillancito & $\begin{array}{c}\text { Sector Plaza } \\
\text { Acevedo }\end{array}$ & $\begin{array}{c}\text { En proceso de } \\
\text { apertura }\end{array}$ & Sin información \\
\hline Pedro de Valdivia & Sin información & $\begin{array}{l}\text { En proceso de } \\
\text { apertura }\end{array}$ & Sin Información. \\
\hline
\end{tabular}

Fuente: elaboración propia a partir de la revisión de “El Sur" 3 de abril, 1919.

\footnotetext{
47 Ídem.

48 ídem.

49 ídem.

${ }^{50}$ BN, El Sur, Concepción, 13 de septiembre, 1918.
} 
Entre los planes trazados y concretados por la primera entidad de auxilio a la infancia pobre y escolar, estuvo el suministro de almuerzo, a fin de dar respuesta a uno de los problemas más recurrentes de la infancia pobre, el hambre, contando en su accionar con el apoyo de la sociedad penquista: "[...] industriales, educacionistas, distinguidas damas $[. . .]^{51}$, además del apoyo fiscal a través de una subvención, posibilitaron ampliar su radio de accionar al tener en funcionamiento seis centros en distintos puntos de la ciudad, pero sin poder concretar -hacia 1919- el objetivo de repartir almuerzos, ya que solo se tiene estadística del número de desayunos diarios repartidos de acuerdo al número de alumnos [...] seleccionados por su pobreza $[\ldots]^{52}$ :

En dos años se entregaban quinientos treinta desayunos, beneficiando a alumnos de dieciséis establecimientos públicos (ver cuadro № 1). Los centros de distribución se ubicaban estratégicamente en distintos puntos de la ciudad y los barrios populares o próximos a estos, por ejemplo, las Escuelas $\mathrm{N}^{\circ} 3$ y $\mathrm{N}^{\circ} 16$ estaban en el sector Ultra Carrera, la Escuela Superior $\mathrm{N}^{\circ} 5$ se encontraba cercana a la calle Prat y al populoso sector de Pedro del Río o Barrio Biobío. De estos barrios provinieron muchos de los alumnos que asistentes a las escuelas públicas fueron beneficiados por El Pan Escolar. Si bien la estadística que presenta el cuadro №1 es parcial, no podemos desestimar la idea que da del radio de acción de El Pan Escolar, pues aproximaba sus centros hacia las zonas más periféricas como Pedro de Valdivia y Chillancito, siendo este último una zona suburbana.

Con casi dos años de funcionamiento, junio de 1917 a abril de 1919, los resultados de esta institución en el ámbito educativo fueron valorados con éxito ${ }^{53}$, el aumento de matrícula en la comuna de Concepción durante el mes de marzo constituyó un dato objetivo para evaluar los efectos de El Pan Escolar en las escuelas públicas: de 4.528 alumnos matriculados, la cifra aumentó a 5.327.

En el ámbito médico ${ }^{54}$, los facultativos, expresaron su apoyo a instituciones como esta, pues a través de una mejora en la alimentación, advirtieron los positivos efectos en la población escolar, "[...] desenvolvimiento físico e intelectual sorprendente $\left[. . .{ }^{55}\right.$, comprobándose las ideas que se difundieron en el Congreso científico de 1909 y la circulación del pensamiento eugenésico en Chile.

El Pan Escolar buscó dar respuesta a los requerimientos más inmediatos a la infancia escolar pobre: alimento y vestuario; sin embargo, quedó pendiente la compleja relación entre

\footnotetext{
${ }^{51}$ BN, El Sur, Concepción, 3 de abril, 1919.

52 Ibídem.

${ }^{53}$ BN, El Sur, Concepción, 30 de abril, 1919.

${ }^{54}$ BN, El Sur, Concepción, 17 de julio, 1919.

${ }^{55}$ BN, El Sur, Concepción, 30 de abril, 1919.
} 
estudiante pobre y salud. La existencia de médicos inspectores fue una realidad solo para las localidades de Santiago y Valparaíso, ya que el ítem del presupuesto en instrucción era inexistente para localidades al sur de la capital; como las enfermedades infecto contagiosas y las epidemias escolares se desarrollaron sin una asistencia médica regular y pagada, la Municipalidad de Concepción, considerando que la aprobación de la Ley de instrucción primaria obligatoria no contempló ningún elemento de auxilio para los escolares pobres, presentó un proyecto al Ministerio del Interior para atender las necesidades médicas de los llamados escolares menesterosos ${ }^{56}$, que funcionó a través de un sistema de policlínico durante la década de 1920, pero que producto de la crisis económica, colapsó en el inicio de la década de 1930.

La aprobación de la Ley de Instrucción primaria obligatoria en 1920 -año en también que se legisló sobre el trabajo infantil fijándose en catorce años el límite legal para la contrataciónestableció la responsabilidad del Estado en materia educativa y en la asistencia obligatoria de tres años a la infancia con un límite de edad de trece años, sin contemplar el auxilio de alimentación escolar y médico a los alumnos más pobres, mutilando la obligación asistencial del Estado respecto de su protección ${ }^{57}$, delegando algunos aspectos del auxilio en las Juntas Comunales de educación. La ley № 3.654 de Instrucción Primaria Obligatoria, que debió haber sido el medio más poderoso para la inclusión real del niño pobre en el sistema educacional y cambiar a través de este la sociedad, fue en realidad una mera declaración, la que al carecer de un sistema de respaldo efectivo, hizo que el Estado continuara delegando en el accionar privado -ya no exclusivamente de la elite, sino de las comunidades locales- el auxilio a la infancia pobre.

“La asistencia escolar, hoi día obligatoria por lei última № 3.654, exije a algunos padres de familia enviar a sus hijos en forma lamentable dada la indigencia en que ellos viven. iSon ciudadanos y por lo tanto olvidan sus miserias ante el cumplimiento de las leyes!

[...] pobrecitos educandos de esta escuela, que, descalzos y sin abrigo vienen a recibir sus lecciones para ser más tarde útiles a su hogar y a su patria" 58 .

Hubo que esperar hasta el año 1928 para el Estado estableciera un servicio médico escolar para las escuelas públicas ${ }^{59}$ que atendió a la infancia pobre fijándose en veinticinco visitas mensuales por escuela ${ }^{60}$, aplicó las vacunaciones establecidas para combatir las epidemias y se percató de la alarmante presencia de sarna en la población escolar, como una manifestación concreta de los problemas de salubridad que afectaba sus hogares ${ }^{61 .}$

\footnotetext{
${ }^{56}$ BN, El Sur, Concepción, 30 de abril, 1921.

57 Illanes O., Ausente señorita...p.100

${ }^{58}$ BN, El Sur, Concepción, 5 de junio, 1921.

${ }^{59}$ BN, El Sur, Concepción, 28 de diciembre, 1928.

${ }^{60}$ BN, El Sur, Concepción, 20 de marzo, 1929.

${ }^{61}$ BN, El Sur, Concepción, 17 de octubre, 1929.
} 


\section{Otras sociedades de auxilio a la infancia escolar pobre}

Considerando la disposición de obligatoriedad y la pobreza del estudiantado, en Concepción surgieron iniciativas de auxilio desde los propios docentes y vecinos de los barrios donde se emplazaron las escuelas, para poder dar cumplimiento a la ley y promover la ayuda material como mecanismo que promoviera la permanencia de la infancia en los establecimientos municipales.

El año clave para el fortalecimiento la asistencia escolar privada fue 1921 a partir de la creación de nuevas organizaciones, que nos permiten comprender los niveles de pobreza de los escolares, manifestación concreta de las paupérrimas condiciones de vida, en donde el hambre y la miseria material fueron subsanados a través de entrega de desayunos, almuerzos y ropa, en un contexto en el que uno de los principales temores era la decadencia de la raza -y la necesidad de salvación de esta- y las enfermedades sociales, siendo los escolares pobres una manifestación de ambos temores.

De esta manera se organizó la Sociedad Protectora de estudiantes proletarios ${ }^{62}$, el Comité pro-niños desvalidos de la Escuela Superior № $3^{63}$, la Sociedad Protectora de la Escuela de niñas №3 $8^{64}$ y la Sociedad de Estudiantes Proletarios ${ }^{65}$, agrupaciones que centraron sus esfuerzos en complementar el accionar de El Pan Escolar en la repartición de vestuario y alimentos ${ }^{66}$,

"[...]tanto ser desgraciado que a las puertas de la miseria, acelera la muerte y la ignorancia, beneficiando a niños para que asistan a la escuela [...] $]^{67}$; "Se repartió a las agraciadas 53 delantales, 23 vestidos, 54 piezas de ropa interior, una docena de medias, una docena de calzado hecho sobre medida y de buen material" ${ }^{68}$.

Un punto central es que estas nuevas sociedades o ligas funcionaron atendiendo las necesidades de escuelas específicas, a diferencia de El Pan Escolar, sin embargo la Sociedad de estudiantes proletarios, al percatarse de la necesidad de alimentación, producto del hambre que experimentaba la infancia, "[donde] no faltaban niños que se desmayaban por debilidad"69, consideró necesario incorporar a la entrega de desayunos escolares a alumnos de la escuela № 30 ubicada en Pedro del Río Zañartu, además de las escuelas № 25, № 7 y № 20,

\footnotetext{
62 BN, El Sur, Concepción, 6 de junio, 1921.

${ }^{63}$ BN, El Sur, Concepción, 13 de junio, 1921.

${ }^{64}$ BN, El Sur, Concepción, 17 de junio, 1921.

65 BN, El Sur, Concepción, 8 de octubre, 1921.

${ }^{66}$ BN, El Sur, Concepción, 24 de agosto, 1921.

${ }^{67}$ BN, El Sur, Concepción, 31 de julio, 1921.

${ }^{68}$ BN, El Sur, Concepción, 10 de julio, 1921.

${ }^{69}$ BN, El Sur, Concepción, 28 de abril, 1922.
} 
transformándose en una entidad de auxilio de gran impacto para la infancia pobre, al atender las necesidad de escuelas de Concepción, Chiguayante y Talcahuano ${ }^{70}$, contando en un período de un año con quinientos estudiantes protegidos ${ }^{71}$; para financiar sus actividades desarrollaron distintos eventos ${ }^{72}$ como bailes, funciones de cine, entre otros, alcanzando gran apoyo por parte de la sociedad penquista ${ }^{73}$, haciendo posible que esta sociedad inaugurara un comedor escolar cocina en la escuela № $20^{74}$, entregando ayudas a domicilio y repartiendo ropas $^{75}$.

“Ayer la sociedad protectora de estudiantes pobres repartió ropas. Durante la repartición de las ropas, tuvimos ocasión de presenciar conmovedoras escenas de chiquitines harapientas hasta lo increíble, cuyo contento no tenía límites al recibir de las manos caritativas, [...] un regalo de ropa nueva que tal vez solo vieron en sus sueños blancos. [...]hubo algunos que no recibieron y quedaron muy tristes [...]"

Cada repartición de ropas iba acompañada de un discurso, en el que encontramos tanto los elementos característicos de la filantropía laica, como los discursivos que nos indican que la educación fue concebida como un mecanismo fundamental para la progresión intelectual e higiénica, de la raza en definitiva, de la infancia pobre, especialmente en el caso de las escuelas de niñas ${ }^{77}$.

"El deseo de vuestros protectores es que seais ordenadas, aseadas en cuanto sea posible, cuidadosas de vuestros vestidos por modestos que sean, mantened diariamente vuestro cuerpo limpio, recordando que la pobreza no impide efectuar vuestras reglas de higiene para conservar la salud. Estén siempre peinados vuestros cabellos, limpia vuestra dentadura y os evitareis sufrimientos"78.

La Sociedad de estudiantes proletarios, destacó por sobre sus pares por su radio de acción alcanzado, gracias a los recursos que económicos que dispuso ${ }^{79}$, proporcionando para la infancia pobre que concurrió a las múltiples escuelas que asistió, 1.500 prendas de ropa ${ }^{80}$. Como actividad que marcó el inicio del año escolar, fundó una nueva cocina escolar en la escuela №

\footnotetext{
${ }^{70}$ BN, El Sur, Concepción, 25 de octubre, 1922

${ }^{71}$ BN, El Sur, Concepción, 22 de junio, 1923.

72 BN, El Sur, Concepción, 6 de junio, 1923

${ }^{73}$ BN, El Sur, Concepción, 2 y 3 de septiembre, 1922

${ }^{74} \mathrm{BN}$, El Sur, Concepción, 8 de mayo, 1923.

${ }^{75}$ BN, El Sur, Concepción, 15 de octubre, 1923.

${ }^{76}$ BN, El Sur, Concepción, 22 de junio, 1923

${ }^{77}$ BN, El Sur, Concepción, 23 de julio, 1924.

${ }^{78} \mathrm{BN}, \mathrm{El}$, Sur, Concepción, 15 de octubre, 1923.

${ }^{79}$ BN, El Sur, Concepción, 6 de febrero, 1925

${ }^{80}$ BN, El Sur, Concepción, 31 de marzo, 1924.
} 
6, "[...] recibiendo la cooperación de comerciantes del mercado" ${ }^{81}$, beneficiando a los niños asilados del hospicio ${ }^{82}$ en sus múltiples reparticiones de ropa. Sin embargo, hacia 1927 la sociedad enfrentó una crisis económica como consecuencia de un incendio que les privó del espacio destinado a los eventos y de los artículos de auxilio para los escolares pobres de Concepción ${ }^{83}$; ante esta situación la colaboración de la comunidad no se hizo esperar y rápidamente se organizaron colectas ${ }^{84}$ y bailes $^{85}$ en beneficio de sociedad de estudiantes proletarios $^{86}$.

Entre las otras instituciones de auxilio fundadas con posterioridad a la ley de instrucción primaria obligatoria, se destaca la Sociedad José Mercedes García, que protegió a las alumnas de la escuela № 3, sin cuya existencia “[...] no podían asistir a sus clases debido a su estremada pobreza" ${ }^{87}$; recibiendo no solo vestuario y alimentación (almuerzos) -inicialmente una vez a la semana-, sino que también la enseñanza de hábitos higiénicos, en sintonía con las propuestas provenientes del mundo médico "tras el primer almuerzo, la directora sra. Mirna Riffo de Mayorga, dictó mensajes sobre higiene pidiéndoles que usaran continuamente el cepillo de dientes, con la cual se libran de infecciones. Se les regaló también toallas, peinetas, jabón, cepillo y pasta de dientes" 18 .

En junio de 1927 emergió en la ciudad la Sociedad Protectora y extensión escolar Pedro de Valdivia, agrupación que contó con el apoyo director del Rotary Club, que persiguió los mismos fines que las otras sociedades destinadas al auxilio de la infancia pobre en las escuelas: el vestuario y la alimentación, centrando su accionar en el barrio Pedro de Valdivia y repartiendo entre los hogares más necesitados el vestuario ${ }^{89}$ requerido y estableciendo la entrega de desayunos a los escolares del barrio ${ }^{90}$.

Cada una de las sociedades posibilitó la asistencia de los niños pobres a las escuelas de la ciudad, aplicándose las miradas provenientes desde la medicina y la opinión pública sobre la utilidad de ello. Además del progreso de la nación, el combate del analfabetismo, la instrucción moral e higiénica que recibirían los estudiantes pobres serían de gran beneficio para la condición de salubridad pública y privada, siendo la escuela y estas sociedades más que

\footnotetext{
${ }^{81}$ BN, El Sur, Concepción, 26 de junio, 1925

82 BN, El Sur, Concepción, 15 de julio, 1926

${ }^{83}$ BN, El Sur, Concepción, 12 de enero, 1927

${ }^{84}$ BN, El Sur, Concepción, 19 de enero, 1927.

85 BN, El Sur, Concepción, 20 de enero, 1927.

${ }^{86} \mathrm{BN}$, El Sur, Concepción, 15 de enero, 1927.

${ }^{87}$ BN, El Sur, Concepción, 24 de octubre, 1921.

88 Ídem.

89 BN, El Sur, Concepción, 17 de junio, 1928.

90 BN, El Sur, Concepción, 17 de junio, 1928.
} 
mecanismos que permitieran la instrucción, sino que también la formación de hábitos de moralidad e higieneen cada uno de los estudiantes penquistas y chilenos a fin de combatir los males sociales y la decadencia de la raza ${ }^{91}$.

\section{Conclusiones}

Las problemáticas sociales que se desarrollaron en el país desde la segunda mitad del siglo XIX fueron abordadas a través de una doble mirada: la médica o científica que terminó transformándose en un elemento fundamental dentro de las funciones sociales que adquirió el Estado durante la década del '20, pero además las interpretaciones que la propia sociedad, en este caso la élite y los sectores medios, realizaron de ella.

En el contexto de un país que transitaba hacia la conmemoración de su primer centenario y demostraba con ello el progreso alcanzado en los cien años de historia republicana, en donde un punto central era establecer el triunfo de la civilización frente a la barbarie, se hacía evidente que esta seguía estando presente a través de la vida en el conventillo, la mendicidad infantil, la mortalidad producto de la falta de higiene pública y privada, los altos índices de alcoholismo, el desarrollo de las epidemias y la configuración de las llamadas enfermedades sociales o de trascendencia social, tuberculosis, sífilis y alcoholismo. Estas diezmaban a la población y legaban a sus descendientes una serie de estigmas, los que se hacían visibles sobre todo en el caso de la infancia pobre. La "raza chilena", se encontraba enferma, había experimentado una degeneración producto de sus condiciones de vida, lo que se plasmaba en los índices vitales y era una realidad innegable, demostrando así que era necesario fortalecer las prácticas provenientes del higienismo a través de desinfecciones, inspecciones, multas y nuevas construcciones; la "degeneración de la raza" debía ser contenida a través de medidas como por ejemplo la organización de las Gotas de leche y la aplicación de las ideas eugénicas que terminaron circulando en los círculos médicos y permitieron la creación de todo un corpus científico y teórico en la formación de los facultativos chilenos.

Tanto los médicos, industriales y el resto de la sociedad descubrieron las formas de vida de los más pobres centrándose en el conventillo, las dinámicas familiares que se generaban en torno a él, los niveles de salubridad y el impacto de este para la población desde los principios científicos, económicos -la productividad- y filantrópicos, para una nación que buscaba progresar en el ideario liberal. Por ello y considerando el porvenir de la nación, la mirada de los médicos y de la élite se centró en la infancia pobre a través de dos variables: la enfermedad y la escolaridad, las que no pueden ser analizadas de manera independiente, sino que se encuentran estrechamente vinculadas, ya que tendrían su punto de inicio en las paupérrimas condiciones de vida que experimentaba la infancia popular y en particular las condiciones de

${ }^{91}$ BN, El Sur, Concepción, 23 de mayo, 1928. 
higiene y alimentación; ello explica el por qué se crearon una serie de instituciones que atendieron estas dos problemáticas, como por ejemplo la Sociedad protectora de la Infancia y la Gota de leche. Sin embargo, esas instituciones excluyen a la infancia pobre en edad escolar.

La valorización que la clase política de filiación liberal-radical le dio a la educación como elemento central del progreso de la nación, en el entendido que en el analfabetismo se encontraba el origen de algunos males sociales y que por ello la apertura de escuelas constituiría el mejor mecanismo para el cierre de cárceles, la escuela fue vista como el medio efectivo para combatir la delincuencia, tal como se aplicó por el municipio de Concepción cuando se ordenó la detención y posterior citación de los padres de aquellos niños aprehendidos por vagos obligándoles a matricularse en un establecimiento. Si bien la medida estadísticamente aumentó el número de escolares matriculados, no se tradujo en una incorporación permanente a la escuela. Además, la propia pobreza de quiénes asistían a las escuelas públicas se haría más evidente al aprobarse la ley de instrucción primaria obligatoria, por ello el proyecto original propuesto por Pedro Bannen incluía el sistema de auxilio de alimentación y material para lograr la permanencia real de los estudiantes en la escuela y de paso, mejorar las condiciones física de estos siguiendo las recomendaciones y observaciones de la médico Eloísa Díaz en su calidad de profesional.

Los estudiantes pobres encarnaban la degeneración de la nación, su estado físico llamó la atención de los médicos y su presentación personal, descalzos, desaseados y vistiendo en harapos conmovió a la sociedad. Fueron los profesores, vecinos de los barrios, comerciantes los que sensibilizados por el estado de los escolares pobres, más la circulación de las ideas provenientes del mundo científico representado en los médicos y difundidos por la prensa, fuertemente influenciados en su formación por las ideas del higienismo- que se habían aplicado en la ciudad desde el siglo XIX- la degeneración de la raza y la eugenesia, quienes generaron el ambiente propicio para la formación de sociedades de auxilio para los escolares pobres, siendo la primera El Pan Escolar, que suplió la necesidad de alimento y vestuario de la infancia escolar pobre y gracias a las gestiones de sus socios, alcanzó una subvención fiscal, mecanismo tradicional de la intervención del Estado liberal, transformando en un referente para la sociedad penquista.

La aprobación de la ley de instrucción primaria, sin auxilio escolar, constituyó el punto de inflexión que motivó la organización de nuevas instituciones, las cuales al aproximarnos a sus actividades y discursos emitidos, constatamos claramente que sirvieron como un catalizador no solo de la ayuda necesaria para los escolares pobres, sino que además promovieron las ideas del mundo médico: frente a una raza degenerada, era necesaria la intervención y la difusión de prácticas de higiene y moralidad para la defensa de la raza, siendo estas en definitiva el punto de encuentro entre aquellos preocupados por la educación y condición moral e intelectual - la sociedad- y el mundo médico que observaba cómo vivían los más pobres, quedando pendiente 
la revisión de cómo eran descritos estos en los escritos científicos difundidos en las revistas de medicina.

\section{Fuentes y bibliografía}

\section{Fuentes primarias}

Biblioteca Central Luis David Cruz Ocampo, Universidad de Concepción.

- Actas de la Junta de Beneficencia de Concepción 1880-1939.

- Biblioteca Nacional, “El Sur”, 1886-1929.

\section{Bibliografía}

Benedetti, R. 2011. La cuestión social en Concepción y en los centros mineros de Coronel y Lota 18851910, Concepción, Al aire libro.

Burns, B. 2015. La pobreza del progreso: América Latina en el siglo XIX, Mexico D.F., Siglo XXI editores.

Chávez, P. 2019. "Ilegitimidad, alcoholismo y tuberculosis: explicaciones médicas de la mortalidad infantil. Santiago de Chile (1870-1912)", Nuevo Mundo Mundos Nuevos, consultado el 11 diciembre 2019. https://journals.openedition.org/nuevomundo/76861

Deichler, C. 2016. Historia de la alimentación popular. Dos décadas de lucha médica contra la desnutrición en el Chile urbano, 1930-1950, Santiago, Ministerio de Salud.

Egaña, L. 2000. La educación primaria y popular en Chile. Una práctica de política estatal, Santiago, Dirección de Bibliotecas, Archivos y Museos.

Fernández, P. 2012. “¿Madres desnaturalizadas o socialización de la violencia? Abandono, maltrato e infanticidio en Concepción. 1840-1870", en Revista de Historia Udec №18, Concepción, pp.105-137.

Folchi, D. 2007. "La higiene, la salubridad pública y el problema de la vivienda popular en Santiago de Chile, 1843-1925", en Lopez, R. (coord.). Perfiles habitacionales y condiciones ambientales. Historia urbana de Latinoamérica, siglos XVII-XX, Puebla, Benemérita Universidad Autónoma de Puebla, pp.361-388.

Garcés, D. 2003. Crisis social y motines populares en el 1900, Santiago, LOM.

Grez, T. 1992. La cuestión social en Chile ideas y discursos precursores (1804-1902), Santiago, Dirección de Archivos, Bibliotecas y Museos.

Ibarra, R. 2006. Sociedad Protectora de la infancia de Concepción: la figura de Leonor Mascayano Polanco, Concepción, Universidad de Concepción, Centro de investigación histórico en estudios regionales.

Illanes, M. 1991. Ausente señorita. El niño-chileno, la escuela -para pobres y el auxilio. Chile 1890-1990, Santiago, Junta Nacional de Auxilio Escolar y Becas (JUNAEB).

Illanes, O. 2006. Cuerpo y sangre de la política. La construcción histórica de las Visitadoras Sociales (18871940), Santiago, LOM.

Pinto, J. 2003. La formación del Estado y la nación y el pueblo mapuche. De la inclusión a la exclusión, 2ạ edición, Santiago, Dirección de Bibliotecas, Archivos y Museos.

Rojas, M. 2016. Historia de la Infancia en el Chile Republicano, tomo I y II, Santiago, ediciones Junji.

Salas, D. 1912. El problema nacional: bases para la reconstrucción de nuestro sistema escolar primario, Santiago, Sociedad Imprenta y Litografía Universo.

Salazar, G., Pinto, J. 2002. Historia Contemporánea de Chile IV. Hombría y feminidad, Santiago, LOM. 
Sánchez, M. 2016. Chile y Argentina en el escenario eugénico de la primera mitad del siglo XX, Santiago, Facultad de Filosofía y Humanidades. Tesis para optar al grado de Doctor en Estudios Latinoamericanos.

Yañez, J. (Coord). 2018. Gobernar es alimentar. Discursos, Legislación y políticas de Alimentación popular: Chile, 1900-1950, Santiago, América en Movimiento.

Vicuña, M. 2001.La belle epoque chilena: alta sociedad y mujeres de elite en el cambio de siglo, Santiago, Sudamericana. 